Hydrol. Earth Syst. Sci., 15, 3033-3041, 2011

www.hydrol-earth-syst-sci.net/15/3033/2011/

doi:10.5194/hess-15-3033-2011

(C) Author(s) 2011. CC Attribution 3.0 License.

\title{
Scaling and trends of hourly precipitation extremes in two different climate zones - Hong Kong and the Netherlands
}

\author{
G. Lenderink ${ }^{1}$, H. Y. Mok ${ }^{2}$, T. C. Lee ${ }^{2}$, and G. J. van Oldenborgh ${ }^{1}$ \\ ${ }^{1}$ Royal Netherlands Meteorological Institute, De Bilt, The Netherlands \\ ${ }^{2}$ Hong Kong Observatory, Hong Kong, China \\ Received: 27 April 2011 - Published in Hydrol. Earth Syst. Sci. Discuss.: 11 May 2011 \\ Revised: 2 September 2011 - Accepted: 21 September 2011 - Published: 29 September 2011
}

\begin{abstract}
Hourly precipitation extremes in very long time series from the Hong Kong Observatory and the Netherlands are investigated. Using the $2 \mathrm{~m}$ dew point temperature from $4 \mathrm{~h}$ before the rainfall event as a measure of near surface absolute humidity, hourly precipitation extremes closely follow a $14 \%$ per degree dependency - a scaling twice as large as following from the Clausius-Clapeyron relation. However, for dew point temperatures above $23^{\circ} \mathrm{C}$ no significant dependency on humidity was found. Strikingly, in spite of the large difference in climate, results are almost identical in Hong Kong and the Netherlands for the dew point temperature range where both observational sets have sufficient data. Trends in hourly precipitation extremes show substantial increases over the last century for both De Bilt (the Netherlands) and Hong Kong. For De Bilt, not only the long term trend, but also variations in hourly precipitation extremes on an inter-decadal timescale of $30 \mathrm{yr}$ and longer, can be linked very well to the above scaling; there is a very close resemblance between variations in dew point temperature and precipitation intensity with an inferred dependency of hourly precipitation extremes of 10 to $14 \%$ per degree. For Hong Kong there is no connection between variations in humidity and those in precipitation intensity in the wet season, May to September. This is consistent with the found zero-dependency of precipitation intensity on humidity for dew points above $23^{\circ} \mathrm{C}$. Yet, outside the wet season humidity changes do appear to explain the positive trend in hourly precipitation extremes, again following a dependency close to twice the Clausius-Clapeyron relation.
\end{abstract}

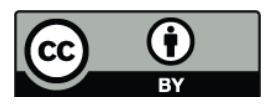

Correspondence to: G. Lenderink (lenderin@knmi.nl)

\section{Introduction}

It is generally conceived that the intensity of precipitation extremes will increase as the climate warms (IPCC, 2007). The primary reason for this expectation is the fact that the maximum moisture content of the atmosphere increases with approximately $7 \%$ per degree temperature rise, which follows from the Clausius-Clapeyron relation (hereafter C-C relation). If the relative humidity does not change, then increases in atmospheric humidity (water vapor) occur at the same rate. Indeed, in models it is generally found that increases in near surface humidity follow the $\mathrm{C}-\mathrm{C}$ relation, in particular over wet surfaces like the ocean, and this can be understood from the surface energy budget (Held and Soden, 2006; Schneider and O'Gorman, 2007; O'Gorman and Muller, 2010; Sherwood et al., 2010). There is observational support for increasing moisture above the oceans (Santer et al., 2007). Above land Willett et al. (2010) also found observed increases of moisture consistent with the C-C relation in many areas, yet with substantial deviations in water limited regions. O'Gorman and Muller (2010) found a 1$2 \% \mathrm{~K}^{-1}$ lower rate compared to the $\mathrm{C}-\mathrm{C}$ relation over the continents in a large ensemble of GCM results.

Increases of daily precipitation extremes at the rate predicted by the C-C relation have been found in two early studies with global climate model results (Allen and Ingram, 2002; Pall et al., 2007). However, in several recent studies it has been argued that there is no clear reason why changes in precipitation extremes should follow a C-C scaling exactly. Changes in the atmospheric large scale motions (Emori and Brown, 2005), the moist-adiabatic lapse rate (O'Gorman and Schneider, 2009), the dynamics of the clouds (Trenberth et al., 2003) and limitations in moisture increase due to soil water depletion (Berg et al., 2009) can induce deviations from a C-C scaling.

Published by Copernicus Publications on behalf of the European Geosciences Union. 
In two earlier studies we found increases in hourly precipitation extremes of approximately two times the C-C relation from observations of the Netherlands, Belgium and Switzerland for daily mean temperatures above $14{ }^{\circ} \mathrm{C}$ (Lenderink and van Meijgaard, 2008, 2010). There are several questions open to debate concerning this enhanced temperature dependency compared to the C-C relation - a "super" C-C scaling. These questions concern the cause of the observed relation, the generality of the results, the role of humidity, and the applicability of the observed relation to climate change.

Haerter and Berg (2009) argue that the super C-C scaling results from a dependency of the frequency of occurrence of large-scale versus convective precipitation with temperature. Since convective events are by their nature more intense than large-scale events, and convective events become more frequent with rising temperature, this could statistically induce an enhanced temperature dependency. If this is the case, it is unlikely that the found scaling is a good predictor of changes in hourly precipitation extremes due to climate change. Conversely, our hypothesis is that the super C-C scaling is caused by a feedback from the dynamics of the cloud due to latent heat release (Trenberth et al., 2003; Lenderink and van Meijgaard, 2009). In that case, if it is related to how convective storms react to increasing humidity, it could be a good predictor of increases in hourly precipitation extremes in a warmer climate.

Another question is whether (and, if so, at what temperature) there is a limit to the super C-C dependency. There are some indications of such a limit in the results of Lenderink and van Meijgaard (2008, 2010), but the temperature range at which this occurs is not well sampled in the data. Such a limit could have a physical cause (see e.g. below), but the statistical explanation proposed by Haerter and Berg (2009) also implies a limit to the super $\mathrm{C}-\mathrm{C}$ dependency.

Further, the availability of moisture under warm conditions is an important issue. It has been argued that soil drying, and a resulting decrease in relative humidity at high temperatures, could cause a limit to the super C-C scaling of precipitation extremes (Berg et al., 2009). Indeed, this may explain the lower dependency of hourly precipitation extremes, or even decrease with temperature, found in recent studies for Australia and the United States (Hardwick Jones et al., 2010; Shaw et al., 2011). For this reason, Lenderink and van Meijgaard (2010) introduced the dew point temperature as a direct measure of atmospheric absolute humidity. For the Netherlands temperature and dew point temperature give similar results. This is because the relative humidity is approximately constant over a large temperature range, which implies a practically constant offset between temperature and dew point temperature. However, this is likely not a general result.

For these reasons it is of interest to investigate hourly precipitation extremes from stations from a warmer, more tropical climate zone, where precipitation is more dominated by convective systems and where the higher temperature range is well sampled. Here, we investigate a very long time series from 1885 to 2009 of hourly precipitation measured at the Hong Kong Observatory, and compare results with earlier findings.

The length of the observational data from De Bilt (the Netherlands) and Hong Kong also allows us to look at trends and natural variability in hourly precipitation extremes. It is of particular interest to investigate whether trends in extremes can be explained by temperature and/or humidity changes using the above scaling relations. If this is the case, we can have more confidence that the observed scaling can be used as a predictor of the influence of climate change on hourly precipitation extremes.

Finally, we note that there could be a dependency of the scaling of precipitation extremes on the aggregation interval. For instance, Haerter et al. (2010) and Utsumi et al. (2011) found different behaviours between hourly and subhourly precipitation. Here we will not investigate this further since sub-hourly data is not (yet) available for the data studied here, but we note that this could be an important factor which deserves further research.

\section{Data and methods}

\subsection{Observations}

A brief description of the observational data sets follows here. All three data sets have been recorded by the meteorological services according to WMO standards and/or the guidelines provided by the Met Office, and some additional quality checks have been performed on the data; more details are provided in Sect. a of the Supplement. First, we use observations made at the Hong Kong Observatory, located in the urban centre of Hong Kong (hereafter, HKO). Continuous observations of hourly temperature, humidity, and precipitation since 1885 are available, except from 1940 until 1946 during World War II (Lee et al., 2006; Wong et al., 2010). Second, observations at De Bilt in the centre of the Netherlands since 1906 (hereafter, DB). Hourly precipitation is available for the whole period, but before 1950 hourly humidity measurements are lacking. Third, observations of 27 stations within the Netherlands of the last $15 \mathrm{yr}$ from 1995 until 2010 (hereafter, NL). These stations are relatively closely spaced in homogeneous environment - a flat river delta - so that the hourly data of precipitation, humidity, and temperature of separate stations can be pooled together to obtain one large data set containing approximately $400 \mathrm{yr}$ of data (see Supplement of Lenderink and van Meijgaard, 2010 for more details).

Hong Kong, located at the south China coast with the mainland China to the north and the South China Sea to the south, has a sub-tropical type of climate (Heywood, 1953). In cool seasons (roughly between October to April), the weather is dominated by the northeast monsoon with an anticyclone 
over the mainland of China, bringing cool air mass from the north or northeast to Hong Kong. In hot seasons (roughly between May to September), heavy rains are mostly triggered by the onset of the southwest monsoon or a trough of low pressure lying from west to east across the northern part of the South China Sea or along the south China coast. The approach and passage of tropical cyclones from western North Pacific and South China Sea could also bring high winds and heavy rain to the territory. When the sub-tropical ridge over the western Pacific extends westward to cover the south China coastal areas, the weather is sunny and hot.

The Netherlands has a moderate maritime climate with mild winters and relatively cool summers. In winter southwesterly atmospheric circulation patterns dominate with frequent passages of low pressure systems. In summer a weak westerly flow is prevalent. Strong precipitation events in summer mostly occur after a period of warm weather, with a retreating high pressure system over central Europe and a low pressure system approaching from the southwest. Under such conditions atmospheric humidity is high and mesoscale convective systems often develop in France and Belgium during the afternoon, giving rise to extreme precipitation during the evening and night in the Netherlands. In autumn with northwesterly flows convective showers often develop above the warm Northsea water.

\subsection{Analysis scaling}

Relations between temperature and precipitation are difficult to asses because of an ambiguity of causes and effects, in particular over moisture-limited regions and the summer season (Trenberth and Shea, 2005). Most important is the dependency of both temperature and precipitation on the atmospheric circulation conditions (Lenderink et al., 2009). In summer, this causes a negative correlation between mean precipitation and temperature since high pressure systems cause warm weather with at the same time low relative humidity and low precipitation amounts. A prolonged period with dry weather could result in soil moisture depletion, with further reduced surface evaporation and temperature increases (Vautard et al., 2007). This again implies a negative correlation between temperature and precipitation, which could be further enhanced by feedbacks from clouds. Yet, on a climatic time scale warmer temperatures are associated with increasing moisture (as discussed in the introduction) and on a global average precipitation increases. It is this causal relation - temperature increases causing moisture increases, causing increases in precipitation extremes - we are interested in and which we want to derive from present-day observations.

We (partly) circumvented this ambiguity by taking, instead of the temperature, the dew point temperature as a direct measure of moisture in most of the analyses. The dew point temperature follows from
$q_{\mathrm{sat}}\left(T_{\mathrm{d}}\right)=q_{\mathrm{v}}$,

where $q_{\text {sat }}$ is the saturation specific humidity as a function of temperature (omitting the dependency of $q_{\text {sat }}$ on pressure) and $q_{\mathrm{v}}$ the actual specific humidity (or moisture content) of the air. The dew point temperature $T_{\mathrm{d}}$ can be obtained by inverting this equation, and is a measure of absolute humidity. The difference between temperature and the dew point temperature, $T-T_{\mathrm{d}}$ which is commonly referred to as dew point depression, is a direct measure of relative humidity. In firstorder approximation a constant dew point depression implies a constant relative humidity across a reasonable temperature range (since $q_{\text {sat }}$ is approximately an exponential function of $T)$.

A scaling of extreme precipitation intensity was first found as a function of temperature (Lenderink and van Meijgaard, 2008). For the reasons stated above we introduced in Lenderink and van Meijgaard (2010) the daily mean dew point temperature. Here, we will primarily use hourly dew point temperatures. Dependencies of hourly precipitation intensity on the (dew point) temperature are computed using a binning technique following Lenderink and van Meijgaard $(2008,2010)$. Binning is done in classes of $2{ }^{\circ} \mathrm{C}$ width. Bins are overlapping with steps of one degree; this is done to avoid a dependency of the appearance of the plots on the arbitrary choice of the binning intervals, which sometimes occurs when the amount of observations is limited. With the pooled data from The Netherlands (NL) (>400 yr of hourly data) very similar are obtained with a bin width of $1^{\circ} \mathrm{C}$, but with the data from $\mathrm{HKO}$ the number of precipitation events in a bin of $1{ }^{\circ} \mathrm{C}$ becomes too limited to reliably computed the extremes. From the binned data different percentiles are computed from the distribution of wet events. Here, wet events are hours with precipitation amounts larger than or equal $0.1 \mathrm{~mm} \mathrm{~h}^{-1}$ (for examples of these distributions see Supplement, Sect. b). In addition to the percentiles computed from the raw data, the 99th and 99.9th percentile are computed also from a Generalized Pareto Distribution (GPD) (Coles, 2001) fit to the upper $4 \%$ of the data. Uncertainty estimates for the 99th and 99.9th percentiles are derived from the error estimates of the GPD fit. The $98 \%$ confidence interval of this fit is indicated by the shading.

\subsection{Analysis trend}

Long-term trends are computed from a 15 -yr sliding window analysis using data from HKO and DB. For each 15-yr block period, different percentiles are computed from a GPD fit to the upper $10 \%$ of the precipitation observations (conditioned to be wet). The reason to look at the statistics of wet events only is that these are less dependent on variations in the atmospheric circulation (Lenderink et al., 2007), which gives better statistics and enables us to better detect the influence of atmospheric moisture on precipitation extremes. For each month and $15 \mathrm{yr}$ period, the 95th, 99th and 99.5th percentile 

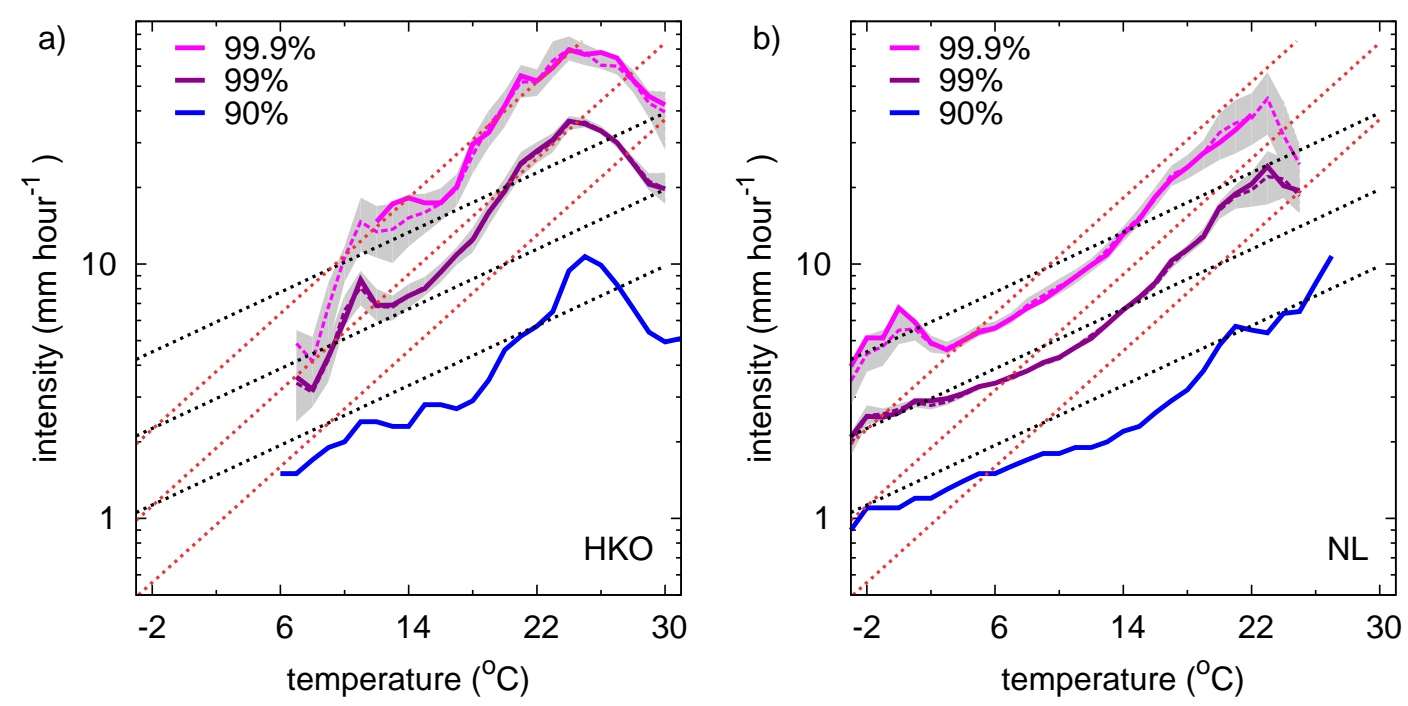

Fig. 1. Dependency of different percentiles of hourly precipitation extremes on daily mean temperature (left: HKO; right: NL). Stippled lines are estimates from the GPD fitting procedure, whereas solid lines are the percentiles computed from the raw data (in most cases these overlap). The grey shading denotes the $98 \%$ uncertainty range derived from the GPD fit. Red (black) stippled lines denote dependencies of $14 \%(7 \%)$ per degree. For comparison, these lines are identical in all plots; the distance between two lines is a factor 2 in intensity.

are first computed from the GPD fit. Anomalies compared to the average of all 15 -yr periods are then computed, and then averaged over several months, e.g. June, July and August (JJA) or the months May until October (MJJASO). This measure is denoted as $\Delta \operatorname{Pr}_{\mathrm{h}}$. Error bands are based on the $98 \%$ confidence interval of the GPD fit procedure, assuming errors of the separate months to be independent. The choice of $15 \mathrm{yr}$ is a compromise between being able to determine the different extremes (which are very noisy with less than $10 \mathrm{yr}$ of data) and being able to capture inter-decadal variations (which are more damped with longer aggregation periods). Here, we use the daily mean dew point temperature because hourly observations are not available for the De Bilt time series before 1950. We note that for the period 1950-2006 similar results are obtained using hourly dew point temperatures.

\section{Scaling of hourly precipitation extremes}

Figure 1 shows scaling relations of hourly precipitation extremes derived using the daily mean temperature for data from the Hong Kong Observatory (HKO) and the 27 stations in the Netherlands (NL). For NL, this is the reproduction of Fig. 1d in Lenderink and van Meijgaard (2010), yet with one year more data for each station. There is clear hint of a decrease in precipitation intensity for temperatures above $24{ }^{\circ} \mathrm{C}$ in NL, but the number of observations with rain above that temperature is very small and consequently the error bands are large. For instance, above $24{ }^{\circ} \mathrm{C}$ there is no observation corresponding to the 99.9th percentile, and this percentile is computed from the extrapolation by means of the GPD fit (indicated by the dashed purple line in Fig. 1). There is a very clear fall off in intensity above $24^{\circ} \mathrm{C}$ in HKO. Since there are many days (about $50 \%$ of days in 1971-2000) with daily mean temperatures above that temperature in HKO, this fall off in intensity is obviously well sampled. Below $24{ }^{\circ} \mathrm{C}$, both data sources show a super C-C scaling. At the same temperature, and for the same percentile, intensities in $\mathrm{HKO}$ are generally larger than those in NL by $20-30 \%$.

Results using the dew point temperature are shown in Fig. 2, where we used the hourly dew point temperature at the time of each hourly rainfall observation (h-0), and from two (h-2) and four hours (h-4) before each rainfall observation. Taking the dew point temperature from four hours before each rainfall observation (h-4) the most consistent scaling is obtained. With consistent we mean here the most constant dependency across the largest range in dew point temperatures. Taking the dew point temperature at the time of the precipitation event $(\mathrm{h}-0)$ less consistent results are obtained, in particular for the high temperature range. This is because the shower affects the dew point temperature by evaporation of precipitation (causing an increase in dew point) and the transport of dry air by the convective downdrafts associated with the shower (causing a decrease in dew point). In particular for the most intense showers often a decrease in dew point temperature is observed during the shower. The dew point temperature from four hours earlier is therefore a better measure of the near surface humidity from the air mass in which the shower develops. To keep the text concise we will omit "taken four hours before each hourly precipitation observation" in the following, and just use "hourly dew point temperature". 

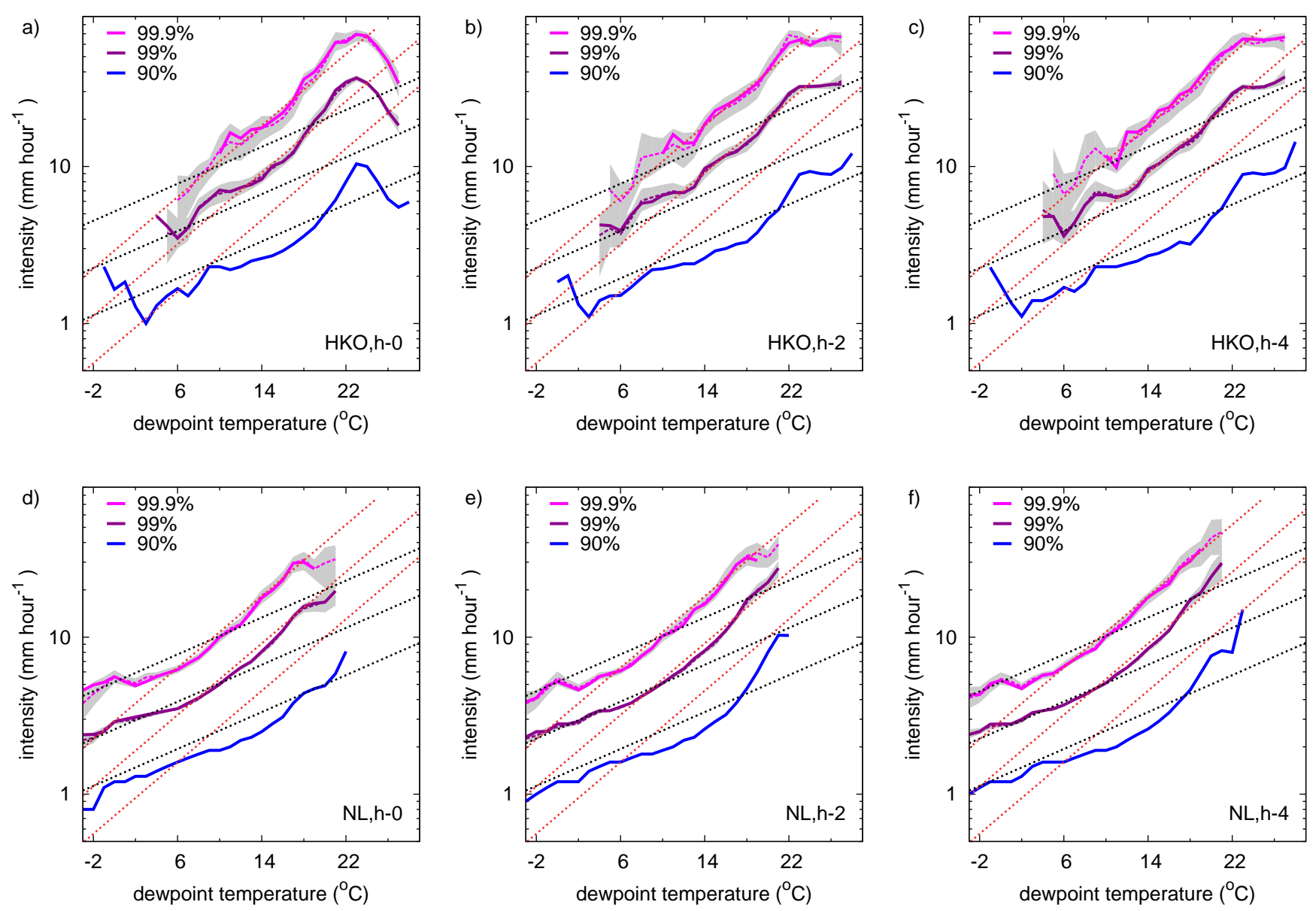

Fig. 2. Dependency of different percentiles of hourly precipitation extremes on dew point temperature taken 0 (h-0), 2 (h-2) and 4 (h-4) h before each precipitation event (upper panels: HKO; lower panels: NL). Lines and symbols are the same as in Fig. 1.

Taking the hourly dew point temperature as predictor, a very well defined scaling is obtained in $\mathrm{HKO}$ and $\mathrm{NL}$ (Fig. $2 \mathrm{c}$ and $\mathrm{f}$ ). In the dew point temperature range between 12 and $20^{\circ} \mathrm{C}$, the 99 th and 99.9 th percentiles are almost identical for both data sources. The dependency is close to $14 \%$ per degree, which is two times the $\mathrm{C}-\mathrm{C}$ relation. Since NL and $\mathrm{HKO}$ are in completely different climate zones, this universality is a striking result.

Results for HKO also clearly show an upper limit for the increase in precipitation intensity with dew point temperature. For dew point temperatures above $23^{\circ} \mathrm{C}$ intensities reach a constant level, which is approximately $65 \mathrm{~mm} \mathrm{~h}^{-1}$ for the 99.9th percentile. Figure 3 shows that about $40 \%$ of all hours have a dew point temperature above $23{ }^{\circ} \mathrm{C}$ taken over the whole year, and in summer (JJA) this percentage is even $90 \%$. Thus it is clear that the range above $23{ }^{\circ} \mathrm{C}$ is well sampled in the HKO data, and that the levelling off is not due to poor sampling or a consequence of rather anomalous atmospheric conditions.

Figure 3 shows that the highest precipitation extremes do not necessarily occur for the highest dew point temperatures, which one might expect from Fig. 2. For all hours with precipitation amounts exceeding the 99th percentile $(\approx$ $10 \mathrm{~mm} \mathrm{~h}^{-1}$ ) in $\mathrm{NL}$, the median dew point temperature is approximately $16{ }^{\circ} \mathrm{C}$. The reason for this is that there are many more precipitation events for the lower and intermediate dew points temperature range than for the highest dew point temperatures (as can be seen from the figures in Sect. b of the Supplement).

By comparing the differences in dew point temperature between extreme and less extreme events (as shown in Fig. 3) a dependency of precipitation extremes on the dew point temperature cannot be inferred. For instance, for summer in NL the difference in intensity between the 90th and 99th percentile is more than a factor two (not shown, but computed from the distribution of all precipitation events in summer). The difference in the corresponding dew point temperatures is only about 1-2 degrees (see Fig. 3) and this would yield a dependency of the precipitation intensity of about $50 \%$ per degree. Obviously, this is not correct and the difference between the two percentiles of hourly precipitation cannot be attributed solely to humidity differences; differences in other 

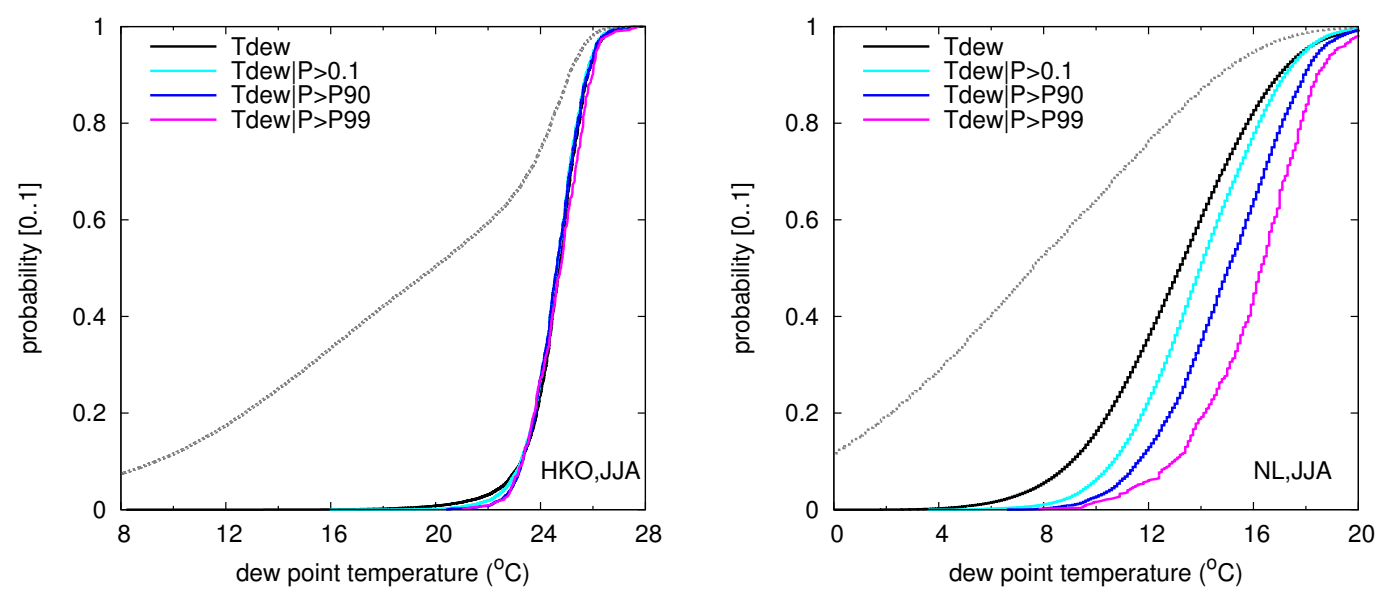

Fig. 3. Cumulative Density Function (CDF) of the dew point temperature for summer (JJA). Distributions of the dew point temperature are plotted for all hours (black line), for hours with precipitation (cyan), and for hours with precipitation exceeding the 90th (blue) and 99th (magenta) percentile of hourly precipitation. As in Fig. 2 dew point temperatures are taken $4 \mathrm{~h}$ before the precipitation event. The grey stippled line gives the CDF of all hours for the whole year.

atmospheric conditions, like the (mesoscale) circulation, vertical instability and wind shear, are all important as well. Thus, by selecting more extreme precipitation events, one inadvertently also samples those atmospheric conditions that, besides humidity, give rise more intense precipitation.

Yet, we note that the cumulative distributions of the dew point temperature from Fig. 3 are qualitatively consistent with the scaling relations in Fig. 2. On the one hand, in HKO almost all extreme events in summer occur with a near surface dew point above $23{ }^{\circ} \mathrm{C}$, where the dependency on moisture is small. Consequently, there is no difference in the distribution of humidity for extreme precipitation events with that occurring on all days. On the other hand, most extreme events in NL occur at humidity levels where the dependency on humidity is still strong: $14 \%$ per degree dew point temperature (Fig. 2). Thus for NL one expects that more extreme precipitation events are characterized by on average higher humidity values as shown in Fig. 3.

\section{Long term trends over the last century}

Figure 4 compares long-term variations in the intensity of hourly precipitation extremes with variations in the dew point temperature (multiplied by $14 \%$ per degree). For DB a very good correspondence between the variations in dew point temperature on days with intense precipitation $\left(\Delta T_{\mathrm{d}}^{*}\right)$ and variations in extreme precipitation $\left(\Delta \operatorname{Pr}_{h}\right)$ is shown for the months May to October (MJJASO). Not only the trend over the century, but also variations on the inter-decadal timescale are very similar. (Days with heavy precipitation are defined as the days on which an hourly precipitation observation exceeds the 90th percentile of the distribution of precipitation on wet hours. Similarly to $\Delta \operatorname{Pr}_{\mathrm{h}}, \Delta T_{\mathrm{d}}^{*}$ is first computed seperately for the different months and then averaged.) The dependency of $\Delta \operatorname{Pr}_{\mathrm{h}}$ on $\Delta T_{\mathrm{d}}^{*}$ however appears somewhat smaller, and the best fit is obtained $11 \%$ per degree (Supplement, Sect. c). For the summer months, June, July, and August, the dependency is $13 \%$ per degree, close to two times the C-C relation. Absolute percentiles of the distribution of hourly precipitation - the 99.5th, 99.9th and 99.95th percentiles - and also the seperate percentiles show very similar time variations (Supplement, Sect. d).

For the wet season May to September (MJJAS) in Hong Kong there is no obvious correspondence between $\Delta \operatorname{Pr}_{\mathrm{h}}$ and $\Delta T_{\mathrm{d}}^{*}$. Both show upward trends, but on an inter-decadal time scale there is no clear connection. This is consistent with the fact that the mean dew point temperature for these months is close to or above the threshold of $23^{\circ} \mathrm{C}$, where Fig. 2 shows no dependency of precipitation extremes on dew point temperature. The reason for the upward trend in $\Delta \operatorname{Pr}_{\mathrm{h}}$ is not further investigated here. It could be related to the urbanization (Kishtawal et al., 2010; Ginn et al., 2010) or changing large scale conditions, like for instance the apparent change in strength of the summer monsoon (Xu et al., 2006; Ding et al., 2008).

Outside the wet season, we could find a reasonably good correspondence between $\Delta \operatorname{Pr}_{\mathrm{h}}$ and $\Delta T_{\mathrm{d}}^{*}$ for the months, October, and February until April (O-FMA). The signal-tonoise ratio, however, is worse than that for DB. In November and December, the number of wet events is so low (approximately $3 \%$ ) that changes in the extremes could not be determined reliably. A regression of $\Delta \operatorname{Pr}_{\mathrm{h}}$ on $\Delta T_{\mathrm{d}}^{*}$ gives a dependency of $13-16 \%$ per degree (Supplement, Sect. c).

Finally, the long term trends in dew point temperature on extreme wet days $\Delta T_{\mathrm{d}}^{*}$ and the average dew 

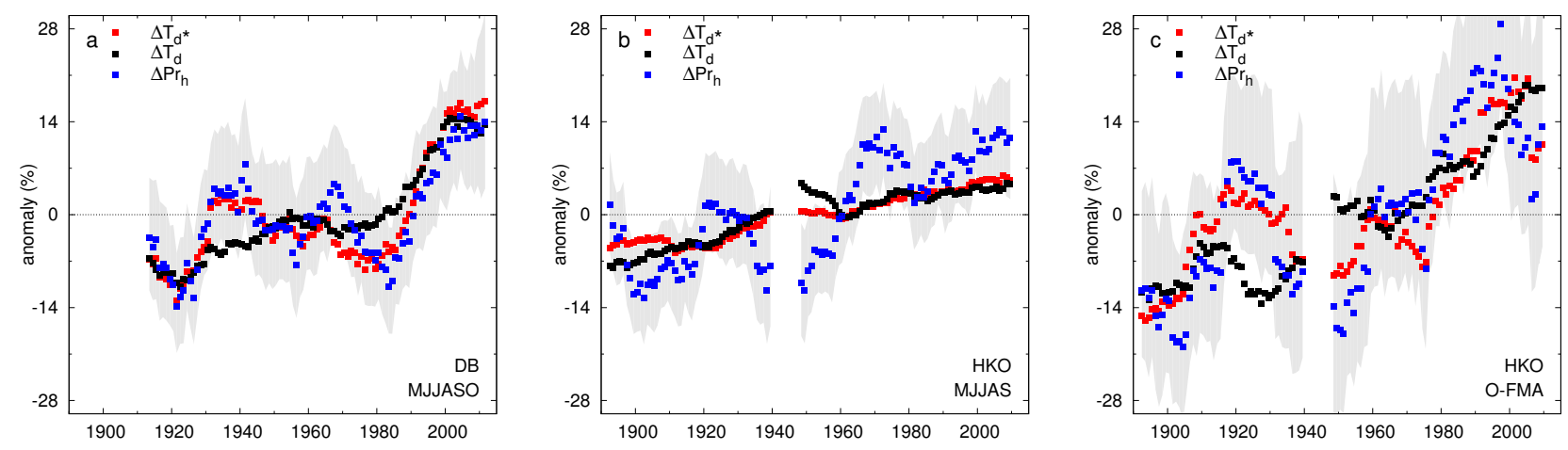

Fig. 4. Variations in hourly precipitation extremes $\left(\Delta \mathrm{Pr}_{\mathrm{h}}\right.$, that is, average over 95th, 99th, 99.5th percentiles) (blue dots)) compared to changes in dew point temperature for heavy precipitation days (with hourly precipitation exceeding the 90th percentile) (red dots) and all days (black dots). Anomalies in dew point temperature are multiplied by $14 \%$ per degree in order to compare the time variations in dew point temperature with those in precipitation intensity. Grey bands are $98 \%$ error estimates of $\Delta \operatorname{Pr}_{\mathrm{h}}$.

point temperature $\Delta T_{\mathrm{d}}$ are very similar, although on the inter-decadal time scale there are differences (Supplement, Sect. e). The long-term trend in $\Delta T_{\mathrm{d}}$ is approximately equal to the trend in the mean temperature, consistent with the hypothesis of a constant relative humidity as climate changes. Thus the long term temperature trend is accompanied with a similar trend in dew point temperature, which on the longer term is reflected in the dew point temperatures when intense showers occur.

\section{Summary and discussion}

The dependency of hourly precipitation extremes on near surface humidity (as measured by the dew point temperature) is investigated in data from the Hong Kong Observatory, in comparison with data from the Netherlands. A dependency of hourly precipitation extremes of $14 \%$ per degree is obtained for dew point temperature up to $23{ }^{\circ} \mathrm{C}$. It is striking that very similar results are obtained for both the Netherlands and Hong Kong for dew point temperatures between 12 and $22{ }^{\circ} \mathrm{C}$, in spite of the large difference in climate. Dependencies of hourly precipitation extremes on the daily mean temperature are less consistent in $\mathrm{HKO}$ and NL. Both show a super $\mathrm{C}-\mathrm{C}$ scaling for temperatures up to $24^{\circ} \mathrm{C}$, and a rapid decrease for higher temperatures.

For dew point temperature above $23{ }^{\circ} \mathrm{C}$, which mainly occur in the time series from Hong Kong, extreme hourly precipitation does not increase further with (near surface) humidity. The reason for this limit is unclear, but could be related to constraints in the micro-physical processes in the convective cloud. Nevertheless, this shows that the premise that a temperature rise, and the resulting humidity rise, leads to increases in precipitation extremes is not necessarily true for the (sub)tropics. This result, obtained from a long time series at one station, contrasts with the large sensitivities of daily precipitation extremes to the sea surface temperature, exceeding the C-C relation, obtained from averaging satellite observations over large areas in the tropics (Allan et al., 2010). A number of global climate models also project changes in precipitation extremes over the tropics exceeding the $\mathrm{C}-\mathrm{C}$ relation, but the spread in global climate model simulations is also large due to contrasting dynamical responses (O'Gorman and Schneider, 2009; Gastineau and Soden, 2009; Allan et al., 2010; Sugiyama et al., 2010). Finally, two studies with a cloud resolving model for the tropics obtained changes in precipitation extremes roughly following the C-C relation (Muller et al., 2011; Romps, 2011). Clearly further research is needed to resolve these differences.

Long-term variations on an inter-decadal to centennial time scale in hourly precipitation extremes are consistent with the above scaling. For the De Bilt (the Netherlands), long-term variations in precipitation extremes in the summer halve of the season can be well explained by changes in surface dew point temperatures following a dependency of 10 $14 \%$ per degree. For Hong Kong, a correspondence between precipitation extremes and dew point temperature could not be established for the wet season May to September, consistent with the finding of a zero-dependency of the precipitation intensity for high dew point temperatures. The reason for the observed increase therefore remains unclear, but could be related to urbanization or changes in the strength of the summer monsoon. For data from October, and February until April, trends in precipitation extremes could be explained reasonably well by moisture changes, again with a dependency close to $14 \%$ per degree.

We relate hourly precipitation extremes to the dew point temperature instead of temperature. This implies that, beside temperature changes, relative humidity changes become important as well. Considering climate change, the simplifying nature of relating changes in precipitation extremes to temperature changes through the Clausius-Clapeyron relation is therefore apparently lost. Only if the relative humidity does 
not change, temperature and dew point temperature changes are equal. However, climate models commonly project considerable decreases in relative humidity over large continental areas in summer. Yet, there could be a twist here. In an ensemble of regional climate simulations over Europe we typically find 50\% smaller spatial variations in the change in dew point temperature compared to the change in temperature (see Supplement, Sect. f). Therefore, changes in dew point temperature may well be more robust and better predictable than changes in temperature. Concluding, we think that the change in dew point temperature provides a physically more justifiable and a more robust indicator of the changes in precipitation extremes than the change in absolute temperature.

We emphasize that the different analyses and the different data sources, all reveal similar dependencies of hourly precipitation extremes on near surface humidity. This strengthens our belief that the found large, 10-14\% per degree, dependency of hourly precipitation extremes on humidity is real, and that it may be used as a predictor of the changes in hourly precipitation extremes due to global warming. If the temperature rises 3 degrees - which is the mean of the projected range of 21 st century warming according to the scenarios issued for the Netherlands (van den Hurk et al., 2007) - the Netherlands may therefore face a $50 \%$ increase of the intensity of hourly precipitation extremes. The societal impact of such an increase could be substantial, for instance for urban flood management.

For Hong Kong, the rising trend of the temperature is expected to continue in the 21 st century (Lee et al., 2011). Outside the wet season, in particular for spring and autumn, the results shows that climate change could have implications for the occurrence of extreme precipitation in Hong Kong. In the wet season, the influence of future warming on the extreme precipitation is likely more complicated, and may involve other mechanisms than the (local) response of showers to increasing atmospheric humidity as discussed in this paper. Further research to understand these mechanisms is clearly needed.

\section{Supplementary material related to this article is available online at: http://www.hydrol-earth-syst-sci.net/15/3033/2011/ hess-15-3033-2011-supplement.pdf.}

Acknowledgements. Financial support from the Dutch project Knowledge for Climate (KfC) to KNMI is gratefully acknowledged.

Edited by: L. Pfister

\section{References}

Allan, R. P., Soden, B. J., John, V. O., Ingram, W., and Good, P.: Current changes in tropical precipitation, Environ. Res. Lett., 5, 025205, doi:10.1088/1748-9326/5/2/025205, 2010.

Allen, M. R. and Ingram, W. J.: Constraints on the future changes in climate and the hydrological cycle, Nature, 419, 224-232, 2002.

Berg, P., Haerter, J. O., Thejll, P., Piani, C., Hagemann, S., and Christensen, J. H.: Seasonal characteristics of the relationship between daily precipitation intensity and surface temperature, J. Geophys. Res., 114, D18102, doi:10.1029/2009JD012008, 2009.

Coles, S.: An Introduction to Statistical Modeling of Extreme Values, Springer Series in Statistics, Springer-Verlag, London, 2001.

Ding, Y., Wang, Z., and Sun, Y.: Inter-decadal variation of the summer precipitation in East China and its association with decreasing Asian summer monsoon. Part I: Observed evidences, Int. J. Climatol., 28, 1139-1161, doi:10.1002/joc.1615, 2008.

Emori, S. and Brown, S. J.: Dynamic and thermodynamic change in mean and extreme precipitation under climate change, Geophys. Res. Lett., 32, L17706, doi:10.1029/2005GL023272, 2005.

Gastineau, G. and Soden, B. J.: Model projected changes of extreme wind events in response to global warming, Geophys. Res. Lett., 36, L10810, doi:10.1029/2009GL037500, 2009.

Ginn, W.-L., Lee, T.-C., and Chan, K.-Y.: Past and Future Changes in the Climate of Hong Kong, Acta Meteor. Sinica, 24, 163-175, 2010.

Haerter, J. O. and Berg, P.: Unexpected rise in extreme precipitation caused by a shift in rain type?, Nat. Geosci., 2, 372-373, 2009.

Haerter, J. O., Berg, P., and Hagemann, S.: Heavy rain intensity distributions on varying time scales and at different temperatures, J. Geophys. Res., 115, D17102, doi:10.1029/2009JD013384, 2010.

Hardwick Jones, R., Westra, S., and Sharma, A.: Observed relationships between extreme sub-daily precipitation, surface temperature, and relative humidity, Geophys. Res. Lett., 37, L22805, doi:10.1029/2010GL045081, 2010.

Held, I. M. and Soden, B. J.: Robust Responses of the hydrological cycle to global warming, J. Climate, 19, 5686-5699, 2006.

Heywood, G. S. P.: Surface pressure-patterns \& weather around the year in Hong Kong, Technical Memoirs 6, Hong Kong Observatory, 19 pp., 1953.

IPCC: Climate Change 2007: The Physical Science Basis. Contribution of Working Group I to the Fourth Assessment Report of the Intergovernmental Panel on Climate Change (IPCC), edited by: Solomon, S., Qin, D., Manning, M., Chen, Z., Marquis, M., Averyt, K. B., Tignor, M., and Miller, H. L., Cambridge University Press, Cambridge, UK and New York, NY, 2007.

Kishtawal, C. M., Niyogi, D., Tewari, M., Pielke, R. A., and Shepherd, J. M.: Urbanization signature in the observed heavy rainfall climatology over India, Int. J. Climatol., 30, 1908-1916, doi:10.1002/joc.2044, 2010.

Lee, T.-C., Leung, W.-M., and Chan, K.-W.: Climatological Normals for Hong Kong 1971-2000, Hong Kong Observatory Technical Note 83, Hong Kong Observatory, 33 pp., 2006.

Lee, T.-C., Chan, K.-Y., and Ginn, W.-L.: Projection of Extreme Temperatures in Hong Kong in the 21st Century, Acta Meteor. Sinica, 25, 1-20, 2011.

Lenderink, G. and van Meijgaard, E.: Increase in hourly precipitation extremes beyond expectations from temperature changes, Nat. Geosci., 1, 511-514, doi:10.1038/ngeo262, 2008.

Lenderink, G. and van Meijgaard, E.: Reply to: Unexpected rise 
in extreme precipitation caused by a shift in rain type?, Nat. Geosci., 2, p. 373, doi:10.1038/ngeo524, 2009.

Lenderink, G. and van Meijgaard, E.: Linking increases in hourly precipitation extremes to atmospheric temperature and moisture changes, Environ. Res. Lett., 5, 025208, doi:10.1088/17489326/5/2/025208, 2010.

Lenderink, G., van Ulden, A., van den Hurk, B., and Keller, F.: A study on combining global and regional climate model results for generating climate scenarios of temperature and precipitation for the Netherlands, Clim. Dynam., 29, 157-176, doi:10.1007/s00382-007-0227-z, 2007.

Lenderink, G., van Meijgaard, E., and Selten, F.: Intense coastal rainfall in the Netherlands in response to high sea water temperatures: analysis of the event of August 2006 from the perspective of a changing climate., Clim. Dynam., 32, 19-33, 2009.

Muller, C. J., O'Gorman, P. A., and Back, L. E.: Intensification of precipitation extremes with warming in a cloud-resolving model., J. Climate, 24, 2784-2800, doi:10.1175/2011JCLI3876.1, 2011.

O'Gorman, P. A. and Muller, C. J.: How closely do changes in surface and column water vapor follow Clausius-Clapeyron scaling in climate change simulations?, Environ. Res. Lett., 5, 025207, doi:10.1088/1748-9326/5/2/025207, 2010.

O'Gorman, P. A. and Schneider, T.: The physical basis for increases in precipitation extremes in simulations of 21 st-century climate change, Proc. Nat. Aca. Sci., 106, 14773-14777, 2009.

Pall, P., Allen, M., and Stone, D.: Testing the Clausius-Capeyron constraint on changes in extreme precipitation under $\mathrm{CO}_{2}$ warming, Clim. Dynam., 28, 351-363, 2007.

Romps, D. M.: Response of Tropical Precipitation to Global Warming, J. Atmos. Sci., 68, 123-138, doi:10.1175/2010JAS3542.1, 2011.

Santer, B. D., Mears, C., Wentz, F. J., Taylor, K. E., Gleckler, P. J., Wigley, T. M. L., Barnett, T. P., Boyle, J. S., Brüggemann, W., Gillett, N. P., Klein, S. A., Meehl, G. A., Nozawa, T., Pierce, D. W., Stott, P. A., Washington, W. M., and Wehner, M. F.: Identification of human-induced changes in atmospheric moisture content, Proc. Nat. Aca. Sci., 104, 15248-15253, 2007.

Schneider, T. and O'Gorman, P. A.: Precipitation and its extremes in changed climates, in Proceedings of Hawaiian Aha Huliko'a Winter Workshop, University of Hawaii, 61-66, 2007.
Shaw, S. B., Royem, A. A., and Riha, S. J.: The relationship between extreme hourly precipitation and surface temperature in different hydroclimatic regions of the U.S., J. Hydrometeorol., 12, 319-325, doi:10.1175/2011JHM1364.1, 2011.

Sherwood, S. C., Ingram, W., Tsushima, Y., Satoh, M., Roberts, M., Vidale, P. L., and O'Gorman, P. A.: Relative humidity changes in a warmer climate, J. Geophys. Res., 115, D09104, doi:10.1029/2009JD012585, 2010.

Sugiyama, M., Shiogama, H., and Emori, S.: Precipitation extreme changes exceeding moisture content increases in MIROC and IPCC climate models, Proc. Nat. Aca. Sci., 107, 571-575, 2010.

Trenberth, K. E. and Shea, D. J.: Relationships between precipitation and surface temperature, Geophys. Res. Lett., 32, L14703, doi:10.1029/2005GL022760, 2005.

Trenberth, K. E., Dai, A., Rasmussen, R., and Parsons, D.: The changing character of precipitation., B. Am. Meteorol. Soc., 84, 1205-1217, 2003.

Utsumi, N., Seto, S., Kanae, S., Maeda, E. E., and Oki, T.: Does higher surface temperature intensify extreme precipitation?, Geophys. Res. Lett., 38, L16708, doi:10.1029/2011GL048426, 2011.

van den Hurk, B., Tank, A., Lenderink, G., van Ulden, A., van Oldenborgh, G., Katsman, C., van den Brink, H., Keller, F., Bessembinder, J., Burgers, G., Komen, G., Hazeleger, W., and Drijfhout, S.: New climate change scenarios for the Netherlands, Water Sci. Technol., 56, 27-33, 2007.

Vautard, R., Yiou, P., D'Andrea, F., de Noblet, N., Viovy, N., Cassou, C., Polcher, J., Ciais, P., Kageyama, M., and Fan, Y.: Summertime European heat and drought waves induced by wintertime Mediterranean rainfall deficit, Geophys. Res. Lett., 34, L07711, doi:10.1029/2006GL028001, 2007.

Willett, K. M., Jones, P. D., Thorne, P. W., and Gillett, N. P.: A comparison of large scale changes in surface humidity over land in observations and CMIP3 general circulation models, Environ. Res. Lett., 5, 025210, doi:10.1088/1748-9326/5/2/025210, 2010.

Wong, M. C., Mok, H. Y., and Lee, T. C.: Observed changes in extreme weather indices in Hong Kong, International Journal of Climatology, published online, doi:10.1002/joc.2238, 2010.

Xu, M., Chang, C.-P., Fu, C., Qi, Y., Robock, A., Robinson, D., and Zhang, H.-m.: Steady decline of east Asian monsoon winds, 1969-2000: Evidence from direct ground measurements of wind speed, J. Geophys. Res., 111, D24111, doi:10.1029/2006JD007337, 2006. 